Published as: Epstein, G., \& Gang, I. (2015). "Making aid work: governance and decentralization". In Handbook on the Economics of Foreign Aid. Edited by B. Mak Arvin and Byron Lew. Cheltenham, UK: Edward Elgar Publishing. Retrieved Nov 24, 2015, from <http://www.elgaronline.com/view/9781783474578.00039.xml>.

\title{
Making Aid Work: Governance and Decentralization
}

Gil S. Epstein

Department of Economics, Bar Ilan University, Ramat Gan; IZA, Bonn; CReAM, London gil.epstein@biu.ac.il
Ira N. Gang

Department of Economics, Rutgers

University; IZA, Bonn; CReAM,

London; IOS, Regensburg

gang@economics.rutgers.edu

\section{November 4, 2014}

\begin{abstract}
(146 words)
Donor aid organizations $(D A O s)$ are multi-layered and multi-dimensional bureaucracies with many departments trying to find solutions to problems for countries, investing staff resources and effort into having an effect. A department may come into conflict with other departments because of personal and other rivalries, at least partly overlapping jurisdictions, and/or the bureaucratic necessity of laying claim to having the bigger impact. The idea here is that good governance starts at home. We consider how inter-departmental competition within the DAO affects departments' efforts and the DAO's performance measured by its ability to maximize effort towards helping a client country. In short, we wish to see how alternative reward systems which DAOs may put into place motivate competing departments in implementing the organization's goals. The argument for establishing good governance criteria is as much to put constraints on donor behavior as on the necessity of properly acting recipients.
\end{abstract}

JEL Codes: Economic Development: General (O10); Role of International Organizations (O19); Foreign Aid (F35)

Keywords: foreign aid, governance, rent seeking, decentralization

\section{Correspondence:}

Gil S. Epstein, Department of Economics, Bar-Ilan University, Ramat Gan, 52900, Israel, Email: gil.epstein@biu.ac.il Tel: (972) 528550 407. Fax: 972-3-7384034

Ira N. Gang, Economics Department, Rutgers University, 75 Hamilton St, New Brunswick NJ 08901-1248 USA. email: gang@economics.rutgers.edu Tel : +1 848-932-8648. Fax : +1 732932-7416 
Page 2 of 22 
Page 3 of 22 


\section{Making Aid Work: Governance and Decentralization}

\section{Introduction}

The aid literature generally looks at recipient behavior or the political economy of donor actions (Banks and Hulme, 2012; Brech and Potrafke, 2014; Epstein and Gang, 2009; Lahiri and Raimondos-Moller, 2000, 2004; Nanivajo and Lahiri, 2011). Our intention is to examine a small part of the internal workings of a development aid organization (DAO), studying how the government or board to which it answers can set up a reward system so that the behavior of the $D A O$ is properly aligned with policy.

Development aid organizations are peculiar and complex organizations. Neither Leviathan nor libertarian, they possess multi-layered and multi-dimensional bureaucracies whose parts have overlapping jurisdictions and are in constant competition with one another (Seabright, 2002; Murrell, 2002). These rivalries can be characterized as contests - while the different parts of the organization presumably face the same organizational goals, they struggle to increase their own rewards often at the expense of other parts.

In DAOs multiple departments typically compete for support and rewards from a central administration, a board of directors, or a government. Departments work to try to find solutions to problems faced by different countries. Each department invests resources and effort hoping to win the "competition", increasing its prestige, gaining greater resources, or simply surviving as a unit. A department may come into conflict with other departments because of the development of rivalrous plans, at least partly overlapping jurisdictions, and/or the necessity of laying claim to having the bigger impact. Competition among departments does not mean they engage in specific actions against one another. They may well compete by taking actions to help common recipients.

The structure of the contest among departments can be a key element in the DAO attaining its goals. It turns out that a convenient way for classifying alternative contest structures is the type of mechanism used to reward departments. We consider two viable mechanisms. Using one, the organization's central authority establishes a "winner-take-all" competition in which the department achieving the greatest success in helping a client country wins the entire "reward pot." We call this the absolute-win contest or mechanism. In the second, the 
organization examines the success of each department and proportionally rewards each department. We call this the relative-reward contest.

When there are fractious departments seeking to lead their organization in common cause to help a recipient country, the question we ask is whether, when and for whom does an absolutewin mechanism produce more desirable organizational and client results. Each department is trying to help a client country and receive recognition and reward for doing so. Perhaps each department wants the authority and rewards for implementing its own plan, believing its proposal will best help the countries in need. This rather ethereal goal is termed rent, and our model is one of rent-seeking by the departments. Various conceptualizations of rent are possible in the context of our model. The source of all rent is the DAO. The key to our analysis is who captures the rent and the consequences of rent-seeking for aid recipients under the two mechanisms. We construct a highly stylized model to examine who benefits under each mechanism.

We describe and compare the two mechanisms for rewarding departments' successes. With the absolute-win mechanism the group that puts forth the most effort receives all the rent. In this situation the simultaneous bidders are the departments, and their bids are the actions/investments they undertake. The group that takes the most action, or the group that is perceived to have taken the most action, wins, and acquires all the rent. On the other hand, in the relative-reward mechanism the departments compete against each other and obtain rent relative to the amount of effort invested in the contest. This can be seen as a lottery contest in which each department obtains rent proportional to the effort invested. In both cases, in equilibrium, the rent obtained is a function of the efforts invested by the departments.

Our story is about how incentives can be established so that units of the DAO work to attain its goals rather than follow a course of individual or unit rent seeking. The contests we describe align the behavior of the agents (the departments) with the principal (the DAO's management or the government); i.e., align the behavior by setting up proper incentives (Mookherjee, 1984).We develop economic theory that considers how such a competition affects the resources invested by the departments and the performance of the DAO measured by its ability to maximize efforts towards helping its client country. We wish the see how such reward systems affect the implementation of the development aid organization's goals. 
The next section first describes the model. It implements the relative and absolute decision rules in the context of the model, and compares the implications for each of the concerned parties. A concluding section follows.

\section{The Model}

In an earlier paper we modeled potential aid recipients as competing for funds, where the structure of the competition was determined by the donor based on recipients meeting good governance criteria (Epstein and Gang, 2009). Potential recipients looked at aid as part of the competing objectives they face - some good, some not. The problem for the donor government (and for us in modeling) was to design an aid allocation mechanism that would increase the governance quality of potential recipients. We start from the supposition that the implementation of an aid allocation policy based on good governance does not remove self-interested bureaucrats or corruption from the picture.

As in the earlier paper, here we assume agents respond to a number of influences, including self-interest and the desire to perform well at their jobs, though these may pull them in different directions. Here, however, the agents we speak of are in the donor aid organization $(D A O)$. In other words, we discuss self-interested agents on the donor's side, and assume these agents must be coaxed into carrying out their principal's (for example, their government's) wishes to design and implement the appropriate criteria (for example, the good governance criterion) for aid allocation.

Our approach is to consider an organization whose mandate is to find solutions to problems faced by low income countries. The problem the organization itself faces is how to organize itself internally to best achieve the best outcome. The DAO faces the difficulty of its own proper governance. Imagine $m$ departments with partly overlapping jurisdictions in the $D A O$. Each department shares the organization's objective of finding solutions to problems faced by low income countries, and receives a reward (or rent) offered by the organization for doing so. To further simplify, assume two departments are trying to help the same country and are competing for the reward. The organization needs to establish a mechanism or contest for allocating the rewards that will elicit from the competing departments behavior consistent with the DAO's goals. 
Epstein and Gang (2009) look at the design and structure a donor government places on the contest that takes place among recipient governments. Instead, here we are modeling the design of reward systems that a $D A O$ considers implementing for its own departments in order for it to achieve the outcomes it desires when giving aid. The formal modeling is almost the same; the interpretation is different and here we generalize some of the results.

The maximum reward, $n_{i}$, department $i(i=1,2)$ can receive for helping this country can be thought of as the department's stake in the contest. It is not clear which department has more to gain, namely if $n_{i}$ is greater or smaller than $n_{j}$ for all $j \neq i$. Think of the contest in probabilistic terms: $P r_{i}$ is the probability department $i$ wins the contest and receives a payment or prize of $n_{i}$. The expected payment department $i$ receives is $P r_{i} n_{i}$. One can also look at $P r_{i}$ as the proportion of the prize this department receives in the competition - we can talk interchangeably about proportion of the prize obtained and the probability of winning the contest, keeping in mind the two are equivalent. However, one of the contests we examine naturally lends itself to a discussion in terms of the probability of winning the contest, while the intuition of the second contest is better when thinking about the proportion of the payment obtained.

Each department invests effort $x_{i}$ in trying to help the country in need. Effort, $x_{i}$, can be seen as a monetary value, time, effort, etc., and we assume that the cost of each unit of effort is one unit. Let $w$ denote the net payoff received by a department. The expected net payoff (surplus) for the risk neutral department is

$$
E\left(w_{i}\right)=\operatorname{Pr}_{i} n_{i}-x_{i} \forall i=1,2, \ldots, m .
$$

We assume the proportion of the payment obtained in the contest (or the probability of winning the contest) satisfies the following conditions:

(i) The sum of the proportions of the payment obtained equals one, $\sum_{i=1}^{m} \operatorname{Pr}_{i}=1$, i.e., both departments receive credit for their work, obtaining the appropriate proportion of the payment. An alternative interpretation is a probabilistic one in which the DAO awards only one department the prize for helping this country.

(ii) As a department $i$ increases its effort, it obtains a higher proportion of the payment, $\frac{\partial \operatorname{Pr}_{i}}{\partial x_{i}}>0$. 
(iii) As department $j$, the opponent of department $i$, increases its effort, the proportion of the payment that department $i$ obtains decreases, $\frac{\partial \operatorname{Pr}_{i}}{\partial x_{j}}<0$.

(iv) The marginal increase in the proportion of the payment obtained from the contest decreases with investment in effort, $\frac{\partial^{2} \operatorname{Pr}_{i}}{\partial x_{i}{ }^{2}}<0$ (this inequality ensures that the second order conditions for maximization are satisfied).

(v) Simplifying, we do not discuss the possibility of free riding by departments. One could think of a situation under which the actions of one department positively affect the proportion obtained by the other department, as it is not always known which of the departments was really responsible for the outcome. We overcome this by assuming $\frac{\partial \operatorname{Pr}_{i}}{\partial x_{i}}>0$ and $\sum_{i=1}^{m} \operatorname{Pr}_{i}=1$.

The function $\operatorname{Pr}_{\mathrm{i}}($.$) is usually referred to as a contest success function (CSF). The functional$ forms of the CSF's commonly assumed in the literature satisfy these assumptions (see Nitzan, 1994). Own effort, the other department's effort, the stakes and the contest success function determine the probability of winning the contest.

The departments engage in a contest and we assume a Nash equilibrium outcome. Each department determines the level of its activities $x_{i}$ so that its expected payoff, $E\left(w_{i}\right) \forall i=1,2, . ., m$, is maximized. The first order condition for maximization is given by

$$
\frac{\partial E\left(w_{i}\right)}{\partial x_{i}}=\frac{\partial \operatorname{Pr}_{i}}{\partial x_{i}} n_{i}-1=0_{i}
$$

Equation (2) is satisfied if and only if

$$
\frac{\partial \operatorname{Pr}_{i}}{\partial x_{i}}=\frac{1}{n_{i}}
$$

Thus, given that the proportion has decreasing marginal utility with respect to the level of effort invested, the department with the higher stake from the contest will invest more effort in the contest. For example, if department 1 has the higher stake in the contest compared to department 
2, $n_{1}>n_{2}$, then department 1 will determine its effort, $x_{1}$, such that the marginal proportions are $\frac{\partial \mathrm{Pr}_{1}}{\partial x_{1}}<\frac{\partial \mathrm{Pr}_{2}}{\partial x_{2}}$, in order to increase its proportion of the payment. The department that has a higher stake in winning the contest will make the greatest effort.

Simplifying and without loss of generality assume

$$
n_{1} \geq n_{2}>n_{3} \geq \ldots \geq n_{m}
$$

This simply states that there are two departments that have higher stakes than all the rest of the departments. We focus on these two highest stakes departments.

The DAO in our modeling uses two mechanisms to decide the allocation of the reward among departments for successfully helping the country: (1) a mechanism which rewards only the department making the biggest effort and (2) one that rewards each department according to its relative success. In the former there is one winning department for each country being helped by the $D A O$ even though both departments helped this country. Here the winner of the contest obtains the entire payment. On the other hand, in the latter contest the two departments divide the payments relative to their achievements. These mechanisms do not simultaneously coexist. However, comparing their outcomes provides useful insights, and we compare them after fully detailing each scenario.

\section{Being First is All that Counts}

In this contest the department making the biggest effort wins. This type of contest is defined using the all pay auction; here thinking in terms of the probability of winning the contest enhances our intuition. With this mechanism the probability of winning is a function of the effort invested by departments or those perceived by the organization. (Note that in equilibrium effort is a function of the rents the departments can obtain). The probability of winning in this scenario is 


$$
\operatorname{Pr}_{i}=\left\{\begin{array}{l}
1 \quad \text { if } \quad x_{i}>x_{j} \forall i \neq j \\
\frac{1}{k} \quad \text { if } i \text { ties for the high bid with } k-1 \text { others } \\
0 \quad \text { if } \quad x_{j}>x_{i} \forall i \neq j
\end{array}\right.
$$

It can be verified that there exists a unique symmetric Nash equilibrium as well as a continuum of asymmetric Nash equilibria. In any equilibrium, departments 3 through $m$ invest zero effort in activities with probability one (see Baye, Kovenock, and de Vries, 1996), so that only the two departments that have the highest rents will participate. We conduct our analysis for two departments, departments 1 and 2, and assume without loss of generality, department 1 has greater gain from winning the contest, $n_{1}>n_{2}$. It is clear, therefore, that department 1 is able to bid more than department 2. However, it is not clear how much each will bid in equilibrium. It is a standard result that there are no pure strategy equilibria in all-pay auctions (Hillman and Riley (1989), Ellingsen (1991) and Baye, Kovenock and de Vries (1993, 1996)). Suppose department 2 bids $0<x_{2} \leq n_{2}$. Then the first department's optimal response is $x_{1}=x_{2}+\varepsilon<$ $n_{1}$ (i.e., marginally higher than $x_{2}$ ). But then $x_{2}>0$ cannot be an optimal response to $x_{1}=x_{2}+\varepsilon$ . Also, it is obvious that $x_{1}=x_{2}=0$ cannot be an equilibrium. Hence, there is no equilibrium in pure strategies. There is a unique equilibrium in mixed strategies given by the following cumulative distribution functions (see Hillman and Riley (1989), Ellingsen (1991) and Baye, Kovenock, and de Vries, 1996)): $\quad G_{1}\left(x_{1}\right)=\frac{x_{1}}{n_{2}}$ for $x_{1} \in\left[0, n_{2}\right) \quad$ and $G_{2}\left(x_{2}\right)=1-\frac{n_{2}}{n_{1}}+\frac{x_{2}}{n_{1}}$ for $x_{2} \in\left[0, n_{2}\right)$. The equilibrium c.d.f's show that department 1 bids uniformly on $\left[0, n_{2}\right]$, while department 2 puts a probability mass equal to $\left(1-n_{2} / n_{1}\right)$ on $x_{2}=0$. The expected efforts are $E\left(x_{1}\right)=\int_{0}^{n_{2}} x_{1} d G_{1}\left(x_{1}\right)=\frac{n_{2}}{2}$ and $E\left(x_{2}\right)=\int_{0}^{n_{1}} x_{2} d G_{2}\left(x_{2}\right)=\frac{n_{2}^{2}}{2 n_{1}}$. Note that in the all-pay auction we can think of the designation "leader" as probabilistic - i.e., the stronger department is more likely to win the contest.

We can obtain equilibrium expected efforts, equilibrium probabilities and expected 
payoffs. In the case of only two departments the probability of winning is

$$
\operatorname{Pr}_{i}=\left\{\begin{array}{c}
1 \quad \text { if } \quad x_{i}>x_{j} \\
0.5 \text { if } x_{i}=x_{j} \\
0 \quad \text { if } \quad x_{j}>x_{i}
\end{array}\right.
$$

The expected activity level for each department is

$$
E\left(x_{1}^{*}\right)=\frac{n_{2}}{2} \text { and } E\left(x_{2}^{*}\right)=\frac{n_{2}^{2}}{2 n_{1}} .
$$

The equilibrium probability of winning the contest for each department equals

$$
\operatorname{Pr}_{1}^{*}=\frac{2 n_{1}-n_{2}}{2 n_{1}} \text { and } \operatorname{Pr}_{2}^{*}=\frac{n_{2}}{2 n_{1}}
$$

Each department, respectively, has the expected equilibrium payoff

$$
E\left(w_{1}^{*}\right)=n_{1}-n_{2} \quad \text { and } \quad E\left(w_{2}^{*}\right)=0 .
$$

In equilibrium, the total activity in fulfilling the $D A O$ goals is

$$
E\left(X^{*}\right)=E\left(x_{i}^{*}+x_{j}^{*}\right)=\frac{n_{2}^{2}+n_{2} n_{1}}{2 n_{1}}=\frac{n_{2}\left(n_{2}+n_{1}\right)}{2 n_{1}} .
$$

Notice that if both departments can obtain the same benefit, $n_{1}=n_{2}=n$, the expenditure of each department is $E\left(x_{1}^{*}\right)=\frac{n}{2}$ and $E\left(x_{2}^{*}\right)=\frac{n}{2}$; the probability of winning for each equals one-half, $\operatorname{Pr}_{1}^{*}=\operatorname{Pr}_{2}^{*}=\frac{1}{2} ;$ the expected payoff for each department is zero, $E\left(w_{1}^{*}\right)=E\left(w_{2}^{*}\right)=0$; and the total effort invested equals $X^{*}=n$. 


\section{Sharing the Spoils}

The competition among departments may not require a single winner. Without a winner taking the entire prize each department fights to obtain its maximum possible portion. The contest is characterized using the lottery function $\operatorname{Pr}_{i}=\frac{x_{i}^{r}}{x_{j}{ }^{r}+x_{i}^{r}}$ for $r \leq 2$, where the return to effort is captured by the parameter $r$ (Lockard and Tullock, 2001). If $r$ is allowed to approach infinity this mechanism becomes the absolute-win mechanism where the department that invests in the highest level of activities wins the contest (see Baye, Kovenock and de Vries, 1993, 1996). The idea behind this is that the department with the higher benefit has a weight of infinity and thus will win with probability one and the department with the lower stake will lose with probability one.

For now we assume that $r$ is known and fixed and $r \leq 2$. The expected net payoff (surplus) for the risk neutral department is thus given by

$$
E\left(w_{i}\right)=\frac{x_{i}^{r}}{x_{i}^{r}+x_{j}^{r}} n_{i}-x_{i} \quad \forall i=1,2
$$

The first order condition, as stated in equation (2), which ensures that the department maximizes its expected payoff, is

$$
\frac{\partial E\left(w_{i}\right)}{\partial x_{i}}=\frac{r x_{i}^{r-1} x_{j}^{r}}{\left(x_{i}^{r}+x_{j}^{r}\right)^{2}} n_{i}-1=0 \quad \forall i, j=1,2 i \neq j
$$

The Nash equilibrium outcome of the contest is $x_{i}^{*} \quad \forall i, j=1,2 i \neq j$. Solving (12) for both departments using a Nash equilibrium, we obtain that the level of activities in which each 
department participates equals ${ }^{1}$

$$
x_{i}^{*}=\frac{r n_{i}^{r+1} n_{j}^{r}}{\left(n_{i}^{r}+n_{j}^{r}\right)^{2}} \quad \forall i, j=1,2 i \neq j
$$

Here our intuition is enhanced by thinking in terms of the proportion of the rents obtained from the contest. Therefore, the Nash equilibrium proportion of the rents obtained in the contest equals

$$
\operatorname{Pr}_{i}^{*}=\frac{n_{i}^{r}}{n_{i}^{r}+n_{j}^{r}} \quad \forall i, j=1,2 i \neq j
$$

The expected equilibrium payoff for each department equals

$$
E\left(w_{i}^{*}\right)=\frac{n_{i}^{r}}{n_{i}^{r}+n_{j}^{r}} n_{i}-\frac{r n_{i}^{r+1} n_{j}^{r}}{\left(n_{i}^{r}+n_{j}^{r}\right)^{2}}=\frac{n_{i}^{2 r+1}-(r-1) n_{i}^{r+1} n_{j}^{r}}{\left(n_{i}^{r}+n_{j}^{r}\right)^{2}} \quad \forall i, j=1,2, i \neq j, r<2 .
$$

${ }^{1}$ We obtain from the first order conditions (equation (12)) that

$\forall i, j=1,2 i \neq j, \frac{r x_{i}^{r-1} x_{j}^{r}}{\left(x_{i}^{r}+x_{j}^{r}\right)^{2}} n_{i}=1$, therefore it holds that $\frac{r x_{1}^{r-1} x_{2}^{r}}{\left(x_{1}^{r}+x_{2}^{r}\right)^{2}} n_{1}=1$ and $\frac{r x_{2}^{r-1} x_{1}^{r}}{\left(x_{1}^{r}+x_{2}^{r}\right)^{2}} n_{2}=1$. Using these two equations we obtain that $\frac{x_{2}}{x_{1}} \frac{n_{1}}{n_{2}}=1$ and thus $x_{2}=x_{1} \frac{n_{2}}{n_{1}}$. Substituting $x_{2}\left(x_{2}=x_{1} \frac{n_{2}}{n_{1}}\right)$ into $\frac{r x_{1}^{r-1} x_{2}^{r}}{\left(x_{1}^{r}+x_{2}^{r}\right)^{2}} n_{1}=1$ we obtain that $x_{1}^{*}=\frac{r n_{1}^{r+1} n_{2}^{r}}{\left(n_{1}^{r}+n_{2}^{r}\right)^{2}}$. In a similar way we calculate the optimal level of $x_{2}$. 
We now calculate the total amount of effort invested in the contest by the two departments. In the literature this measure is called rent dissipation and usually has a negative connotation, i.e. the contest designer tries to decrease the rent dissipation. Here rent dissipation can be seen in a positive light as it helps the country needing help. We denote this total effort in equilibrium by $X^{*}$ :

$$
X^{*}=x_{i}^{*}+x_{j}^{*}=\frac{r n_{i}^{r} n_{j}^{r}\left(n_{i}+n_{j}\right)}{\left(n_{i}^{r}+n_{j}^{r}\right)^{2}} \quad \forall i, j=1,2 i \neq j
$$

In the case where the departments are symmetric, i.e., $n_{1}=n_{2}=n$, we would obtain the following: the level of activities of each department equals $x_{i}^{*}=n \frac{r}{4} \quad \forall i, j=1,2 i \neq j$ (remember that $\mathrm{r}$ is less than or equal to 2 and therefore the total expenditure will be at the maximum when $\left.x_{i}^{*}=\frac{n_{i}}{2}\right)$; the Nash equilibrium proportion of the rents obtained from the contest will be equal to one-half, $\operatorname{Pr}_{i}^{*}=\frac{1}{2}$; the expected equilibrium payoff to each department equals $\frac{(2-r) n}{4}$ (once again, remember that $r$ is less than or equal to 2 ), ${ }^{2}$ and finally the total effort in equilibrium equals $X^{*}=\frac{r n}{2}$.

Let us consider how a change in $r$ affects the expected equilibrium payoff $E\left(w_{i}^{*}\right)=\frac{n_{i}^{r}}{n_{i}^{r}+n_{j}^{r}} n_{i}-\frac{r n_{i}^{r+1} n_{j}^{r}}{\left(n_{i}^{r}+n_{j}^{r}\right)^{2}}=\frac{n_{i}^{2 r+1}-(r-1) n_{i}^{r+1} n_{j}^{r}}{\left(n_{i}{ }^{r}+n_{j}{ }^{r}\right)^{2}} \forall i, j=1,2, i \neq j, r<2$ and how it affects total effort in equilibrium, $X^{*}=x_{i}^{*}+x_{j}^{*}=\frac{r n_{i}^{r} n_{j}^{r}\left(n_{i}+n_{j}\right)}{\left(n_{i}^{r}+n_{j}^{r}\right)^{2}} \quad \forall i, j=1,2 i \neq j . \quad$ To simplify our calculations denote by $a$ the relative rent of the second group in relationship to that

${ }^{2}$ For $\mathrm{r}>2$ the equilibrium differs from this one as it is based on mixed and not pure strategies. This is the case in the all pay auction that we previously described. 
of the first group's rent: $a=\frac{n_{2}}{n_{1}}$. Given $a$ we recalculate the expected payoff and total effort in equilibrium as $E\left(w_{i}^{*}\right)=\frac{n_{i}\left(1-(r-1) a^{r}\right)}{\left(1+a^{r}\right)^{2}}$ and $X^{*}=\frac{r n a^{r}(1+a)}{\left(1+a^{r}\right)^{2}} \quad \forall a=\frac{a_{j}}{a_{i}}, i=1,2, r<2$,

where,

$$
\frac{\partial E\left(w_{i}^{*}\right)}{\partial r}=\frac{n_{i}\left(1+a^{2 r}\left(1+\left(r-r^{2}\right) \operatorname{Ln}(a)\right)+r a^{r}\left(2+\left(r^{2}-3\right) \operatorname{Ln}(a)\right)\right)}{\left(1+a^{r}\right)^{2}}
$$

and $\frac{\partial X^{*}}{\partial r}=\frac{n a^{r}(1+a)\left(1+r \operatorname{Ln}(a)+a^{r}(1-r \operatorname{Ln}(a))\right)}{\left(1+a^{r}\right)^{3}}$. As we can see from the above, the effect of a change in the parameter $r$ is ambiguous on the expected payoff and expenditure of the groups. For example, without loss of generality assume $a<1$. Since $\operatorname{Ln}(a)<0$ then for $1<r<\sqrt{3}, \frac{\partial E\left(w_{i}^{*}\right)}{\partial r}>0$ and for $\mathrm{a}=1, \frac{\partial E\left(w_{i}^{*}\right)}{\partial r}>0$ and $\frac{\partial X^{*}}{\partial r}>0$. For $\mathrm{r}<1$ it holds that $\frac{\partial X^{*}}{\partial r}>0$.

\section{Comparing the investment of effort by the departments under Both Mechanisms}

The departments do not have a choice between the two mechanisms we model above. They face what they face, though we can image an organization board considering the alternative schemes. We now compare these two types of contests both from the perspective of the departments and the DAO (which wishes to maximize the effort invested in countries needing help). $X^{*}$ is the aggregate activity of the departments in equilibrium (for the case of stakes that do not depend on the efforts invested by the contestants, see Epstein and Nitzan, 2006a, 2006b, 2007).

Under the relative-reward contest, $\operatorname{Pr}_{i}=\frac{x_{i}^{r}}{x_{j}{ }^{r}+x_{i}{ }^{r}}$ for $r \leq 2$, from (16) we obtain that the total amount of activities carried out is equal to $X_{L}^{*}=x_{i}^{*}+x_{j}^{*}=\frac{r n_{i}^{r} n_{j}^{r}\left(n_{i}+n_{j}\right)}{\left(n_{i}^{r}+n_{j}^{r}\right)^{2}} \quad \forall i, j=1,2 i \neq j$. Under the absolute-win contest, from 
equation (10) we obtain that the total investment into activities is equal to $E\left(X_{p}^{*}\right)=\frac{n_{2}\left(n_{2}+n_{1}\right)}{2 n_{1}}$.

The total amount of expenditure invested in the contest is higher under the relativereward than under the absolute-win regime if

$$
X_{L}^{*}=\frac{r n_{i}^{r} n_{j}^{r}\left(n_{i}+n_{j}\right)}{\left(n_{i}^{r}+n_{j}^{r}\right)^{2}}>\frac{n_{2}\left(n_{2}+n_{1}\right)}{2 n_{1}}=E\left(X_{p}^{*}\right)
$$

Remember that $a$ is defined as the ratio of maximum reward as follows:

$$
a=\frac{n_{2}}{n_{1}}<1
$$

The value of $a$ represents the relative maximum benefits of the departments. Remember that $\frac{n_{2}}{n_{1}}<1$ namely that the maximum benefits department 1 can obtain is higher than that of department 2. As $a$ increases the maximum benefits the departments can obtain become closer to each other and the departments become more symmetric, thus, $a n_{1}=n_{2}$.

Rewriting (17) together with (18) we obtain that equation (17) holds if and only if

$$
X_{L}^{*}=\frac{r n_{1}^{r} a^{r} n_{1}^{r}\left(n_{1}+a n_{1}\right)}{\left(n_{1}^{r}+a^{r} n_{1}^{r}\right)^{2}}>\frac{a n_{1}\left(a n_{1}+n_{1}\right)}{2 n_{1}}=E\left(X_{p}^{*}\right)
$$

Equation (18) holds if and only if

$$
\frac{r a^{r}}{\left(1+a^{r}\right)^{2}}<\frac{a}{2}
$$

As we can see the condition under which the total amount of expenditure invested in the contest is higher under the relative-reward than under the absolute-win regime is not a function of the absolute values maximum reward; it is a function of the relative rewards, $a$. (20) holds true if and only if

$$
2 r<\frac{\left(1+a^{r}\right)^{2}}{a^{r-1}}
$$


Let us consider how the RHS of (21) changes with a change in $a$,

$$
\operatorname{Sing}\left(\frac{\partial\left(\frac{\left(1+a^{r}\right)^{2}}{a^{r-1}}\right)}{\partial a}\right)=\operatorname{Sing}\left((3-r) a^{2 r-2}-(r-1) a^{r-2}\right) .
$$

For $r \leq 2$ it is clear that the sign of (22) increases with $a$ thus for any $r \leq 2$ (remember that $r$ must be smaller than 2) the right side of (21) increases with $a$. Thus, for any given value of $r$ the chances that (20) holds increases with an increase in $a$, and the ratio of the maximum rewards between 1 and 2 increases, thus increasing the variance of the awards in the contest.

Epstein and Gang (2009) and Epstein, Mealem, and Nitzan (2011), study the case of $r=1$ and find that the condition is that $\frac{n_{1}}{n_{2}}>1+\sqrt{2}$. Since, by assumption, $n_{1} \geq n_{2}$, the result tells us that in order for the lottery contest to be worse for the recipient, the rent that one of the departments can obtain from such actions must be larger than the other department's rent (more than twice as large). We summarize this result in the following proposition:

If the variance of rents that can be generated by helping the country is sufficiently large, then the development aid organization which is interested in maximizing its departments' total effort prefers the absolute-win contest where the department that invests the most effort wins. If each department has the same stake, i.e., $n_{1}=n_{2}$, then the development aid organization prefers the relative-reward contest.

In order to analyze the preferences of the departments we must compare their expected payoffs under both the relative-reward and the absolute-win regimes. Remember that we assumed, without loss of generality, that department 1 has at least as large a stake as the second department $\left(n_{1} \geq n_{2}\right)$. The departments prefer the regime that generates for them the maximum expected equilibrium payoff, $E\left(w_{i}^{*}\right)$. Under the relative-reward contest, and again assuming $r=$ 1, the expected equilibrium payoff for department 2 (the weaker player) equals 
$E\left(w_{2}^{*}\right)=\frac{n_{2}^{2 r+1}-(r-1) n_{2}^{r+1} n_{1}^{r}}{\left(n_{1}^{r}+n_{2}^{r}\right)^{2}}$, while the expected equilibrium under the absolute-win equals zero, $E\left(w_{2}^{*}\right)=0$. Therefore, it is clear that,

The weaker department, the department that has less to gain from helping the country, always prefers the relative-reward system.

For the stronger department the expected equilibrium payoff under relative-reward equals $E\left(w_{1}^{*}\right)=\frac{n_{1}^{2 r+1}-(r-1) n_{1}^{r+1} n_{2}^{r}}{\left(n_{1}^{r}+n_{2}^{r}\right)^{2}}$ while the expected equilibrium under absolute-win equals $E_{P}\left(w_{1}^{*}\right)=n_{1}-n_{2}$. The expected payoff for department 1 under the relative-reward regime is greater than that obtained under the absolute-win regime and thus this department prefers the relative-reward regime if

$$
E\left(w_{1}^{*}\right)=\frac{n_{1}^{2 r+1}-(r-1) n_{1}^{r+1} n_{2}^{r}}{\left(n_{1}^{r}+n_{2}^{r}\right)^{2}}>n_{1}-n_{2}=E_{P}\left(w_{1}^{*}\right) .
$$

Remember that (18) $a=\frac{n_{2}}{n_{1}}$, so

$$
\frac{\left(1-(r-1) a^{r}\right)}{\left(1+a^{r}\right)^{2}}>(1+a)
$$

We obtain that (24) holds if and only if

$$
2 r>\frac{\left(1+a^{r}\right)^{2}}{a^{r-1}},
$$


which is the opposite condition derived in (20).

Epstein and Gang (2009) derived this condition for the case of $r=1$ and $0<n_{1}<n_{2}(1+\sqrt{2})$.

In other words,

The department with the higher stake, with more to gain from helping the country, prefers the relative-reward to an absolute-win if the difference between the departments is not sufficiently large.

Note that the interests of the $D A O$ and the strongest department always align.

\section{Conclusion}

The conversation over governance and decentralization in the aid context focusses on the behavior of governments and their leaders, politicians, bureaucrats and related actors in potential aid-recipient countries. For aid to work the argument is made, there must be good governance. Much can be said for this argument. Recipient governments and their related functionaries are, however, not the only key actors in the aid transmission story. Donor organizations interact with both recipients as well as the fund donors' aid allocation decisions. The argument for establishing good governance criteria was as much to put constraints on donor behavior as on the necessity of properly acting recipients.

Here we struggle with another element of this story: behavior within the aid organization responsible for programmatic development - the groups within the recipient infrastructure who design the aid programs. These elemental particles of the aid complex are here referred to by the inglorious name, departments. Donor aid organizations (DAOs) are multi-layered and multidimensional bureaucracies with many departments which work to try to find solutions to problems in different countries, investing staff resources and effort into having an effect. A department may come into conflict with other departments because of personal and other rivalries, at least partly overlapping jurisdictions, and/or the bureaucratic necessity of laying claim to having the bigger impact (Slotin, Wyeth, and Romita, 2010). 
In much of the literature, governance and decentralization are buzzwords for properly functioning aid policy. Allocating aid on the basis of good governance is a "win-win" situation: objective criteria can be established on what constitutes good governance, and aid can be allocated and disbursed on this basis with minimal need for detailed bureaucratic planning, disbursement, and oversight. We argue that these terms and the actions associated with them are useful for aid organizations themselves - they can employ the same types of contests to ensure that the work of the organization itself is consistent with its goals, and the goals are obtained in an efficient and incentive compatible manner. The idea here is that good governance starts at home. We consider how inter-departmental competition within the DAO affects departments' efforts and the DAO's performance measured by its ability to maximize effort towards helping its client country. Practically speaking (which may be odd when we are discussing a theoretical framework) aid is distributed via organizations, and it is the internal workings of the agency which is critical in aid giving. In short, we wish to see how alternative reward systems which DAOs may implement motivate competing departments in implementing the organization's goals.

We build on earlier work (Epstein and Gang, 2009) where donors look at good governance as a way to enhance aid allocation. Drawing on the same modeling, but now internal to the donating organization, we see this framework can aid in our understanding and mechanism design to handle a wide range of potential conflicts in the aid process. Of course, there are many organizations in the aid complex; some operate on a few broad principles, others with very specific manifestos. We assume that their fundamental goal is to help lower income countries. In a highly structured and simple model we characterize and compare two ex-ante regimes: (1) the absolute reward scheme represented by an all-pay auction in which the winner takes all available rents; (2) the relative reward scheme in which the rent allocation rule is a lottery and each department obtains a proportion of their possible rent. In the former regime the equilibrium here is in mixed strategies, the "stronger" department could actually lose the contest and get nothing. However, the expected payoff for the weaker department is zero.

The contests we address are the fractious relationships among departments seeking to help a country in need and to increase their own expected payoff. We are able to derive a very specific condition allowing us to see when each of the concerned parties wins and loses their contests. If the difference between the departments in terms of the rewards they can obtain from 
helping the country is not sufficiently large, all parties - the two departments and the organization itself - prefer the lottery regime relative-reward to an absolute-win. However, if the difference between the departments in terms of the rewards that can be obtained is sufficiently large, then the department with the low benefit, department 2, prefers the relative-reward regime while the other department and the organization prefer absolute-win.

Our approach and analysis goes beyond a standard rent-seeking contest, instead offering new theoretical insights for structuring incentives in development aid organizations when there are competing departments. So, here what we do is see if we can construct or at least examine a set of incentives faced by the people/agents inside an organization that will yield behavior consistent with the goals of the agency, which we can assume to be set by the donor government. 


\section{References}

Banks, Nicola, and David Hulme (2012), 'The role of NGOs and civil society in development and poverty reduction.' Brooks World Poverty Institute Working Paper 171.

Baye, Michael R., Dan Kovenock and Casper G. de Vries (1993), 'Rigging the lobbying process: an application of the all-pay auction', American Economic Review 83(1), 289-294.

Brech, Viktor, and Niklas Potrafke (2014), 'Donor ideology and types of foreign aid.' Journal of Comparative Economics 42(1), 61-75.

Ellingsen, Tore (1991), 'Strategic buyers and the social cost of monopoly', American Economic Review 81(3), 648-657.

Epstein, Gil S. and Ira N. Gang (2009), 'Good governance and good aid allocation', Journal of Development Economics, 89(1), 12-18.

Epstein Gil S. and Shmuel Nitzan (2007), Endogenous Public Policy and Contests, Springer Berlin Heidelberg New York.

Epstein Gil S. and Shmuel Nitzan (2006a), 'Effort and performance in public policy contests', Journal of Public Economic Theory' 8(2), 265-282.

Epstein Gil S. and Shmuel Nitzan (2006b), 'Reduced prizes and increased effort in contests', Social Choice and Welfare, 26(3), 447-453.

Epstein, Gil S. Yosef Mealem, Shmuel Nitzan (2011), 'Political Culture and Discrimination in Contests', Journal of Public Economics, 95 (1-2), 88-93.

Hillman, Arye L. and John G. Riley (1989), 'Politically contestable rents and transfers', Economics and Politics, 1(1), 17-39.

Lahiri, Sajal, and Pascalis Raimondos-Møller (2000), 'Lobbying by ethnic groups and aid allocation.' The Economic Journal 110(462), 62-79.

Lahiri, Sajal, and Pascalis Raimondos-Møller (2004) 'Donor strategy under the fungibility of foreign aid.' Economics \& Politics, 16(2), 213-231.

Lockard, Alan A and Gordon Tullock, eds. (2001), Efficient rent-seeking, chronicle of an intellectual quagmire, Boston: Kluwer Academic Publishers.

Mookherjee, Dilip (1984), 'Optional Incentive Schemes with Many Agents.' Review of Economic Studies, 51(3), 433-446.

Murrell, Peter (2002), 'The interaction of donors, contractors, and recipients in implementing aid for institutional reform.' In Bertin Martens, Uwe Mummert, Peter Murrell, and Paul Seabright, Institutional Economics of Foreign Aid. Cambridge University Press, 69-111.

Nanivajo, Malokele, and Sajal Lahiri (2011), 'Encouraging Trade Liberalization: Theoretical and Empirical Analysis of Foreign Aid as Prize.' Available at SSRN 1886361.

Nitzan, Shmuel (1994), 'Modelling rent-seeking contests', European Journal of Political Economy, 10(1), 41-60.

Seabright, Paul (2002), 'Conflicts of objectives and task allocation in aid agencies'. In Bertin Martens, Uwe Mummert, Peter Murrell, and Paul Seabright, Institutional Economics of Foreign Aid. Cambridge University Press, 34-68.

Slotin, Jenna, Vanessa Wyeth, and Paul Romita (2010), 'Power, Politics, and Change: How International Actors Assess Local Context.' report, International Peace Institute, New York, 26. 